University of Nebraska - Lincoln

DigitalCommons@University of Nebraska - Lincoln

Faculty Publications from the Department of Electrical \& Computer Engineering, Department Electrical and Computer Engineering

$12-24-2001$

\title{
Giant photoresistivity and optically controlled switching in self- assembled nanowires
}

\author{
N. Kouklin \\ University of Nebraska-Lincoln \\ L. Menon \\ University of Nebraska-Lincoln
}

A. Z. Wong

University of Nebraska-Lincoln

Daniel W. Thompson

University of Nebraska-Lincoln, dthompson2@unl.edu

John A. Woollam

University of Nebraska-Lincoln, jwoollam1@unl.edu

See next page for additional authors

Follow this and additional works at: https://digitalcommons.unl.edu/electricalengineeringfacpub

Part of the Electrical and Computer Engineering Commons

Kouklin, N.; Menon, L.; Wong, A. Z.; Thompson, Daniel W.; Woollam, John A.; Williams, P. F.; and Bandyopadhyay, Supriyo, "Giant photoresistivity and optically controlled switching in self-assembled nanowires" (2001). Faculty Publications from the Department of Electrical and Computer Engineering. 2. https://digitalcommons.unl.edu/electricalengineeringfacpub/2

This Article is brought to you for free and open access by the Electrical \& Computer Engineering, Department of at DigitalCommons@University of Nebraska - Lincoln. It has been accepted for inclusion in Faculty Publications from the Department of Electrical and Computer Engineering by an authorized administrator of DigitalCommons@University of Nebraska - Lincoln. 


\section{Authors}

N. Kouklin, L. Menon, A. Z. Wong, Daniel W. Thompson, John A. Woollam, P. F. Williams, and Supriyo Bandyopadhyay 


\title{
Giant photoresistivity and optically controlled switching in self-assembled nanowires
}

\author{
N. Kouklin, L. Menon, A. Z. Wong, D. W. Thompson, J. A. Woollam, P. F. Williams, \\ and S. Bandyopadhyay ${ }^{\text {a) }}$ \\ Department of Electrical Engineering, University of Nebraska, Lincoln, Nebraska 68588-0511
}

(Received 24 July 2001; accepted for publication 10 October 2001)

\begin{abstract}
We report the observation of giant photoresistivity in electrochemically self-assembled CdS and $\mathrm{ZnSe}$ nanowires electrodeposited in a porous alumina film. The resistance of these nanowires increases by one to two orders of magnitude when exposed to infrared radiation, possibly because of real-space transfer of electrons from the nanowires into the surrounding alumina by photon absorption. This phenomenon has potential applications in "normally on" infrared photodetectors and optically controlled switches. (C) 2001 American Institute of Physics.
\end{abstract}

[DOI: $10.1063 / 1.1427156]$

There is significant current interest in self-assembled semiconductor nanostructures produced by electrodeposition of materials in porous anodic alumina film. They possess intriguing magnetic, ${ }^{1}$ electronic $^{2}$ and nonlinear optical properties. ${ }^{3}$ Here, we report a photoelectric property of these structures that may find application in novel "normally-on" infrared photodetectors. Such photodetectors, which are conductive in the absence of infrared radiation, but insulating in the presence of radiation, have multiple uses. For instance, they can be connected in series with the more conventional normally off photodetectors to create complementary devices in which appreciable photocurrent flows only during the switching on or off of the radiation source. Two broad-band complementary detectors with slightly staggered peak frequencies can also be connected in series to make a narrow band detector.

Regimented arrays of $\mathrm{CdS}$ and $\mathrm{ZnSe}$ quantum wires were self-assembled by electrodepositing the semiconductor selectively within the pores of a nanoporous alumina film. The alumina film was produced by dc anodization of an aluminum foil in an acid. Anodization in sulfuric acid results in $10 \mathrm{~nm}$ diam pores whereas anodization in oxalic acid produces $50 \mathrm{~nm}$ diam pores. A raw atomic force micrograph of the top surface of a representative nanoporous alumina film is shown in Fig. 1 where the dark areas are the pores and the surrounding light areas are alumina. Further details of the process of forming the alumina film can be found in Ref. 4 .

We have electrodeposited two different compound semiconductors within the pores: $\mathrm{CdS}$ and $\mathrm{ZnSe}$. CdS was electrodeposited by immersing the alumina film (along with the aluminum substrate) in an electrolyte consisting of a nonaqueous solution of dimethyl-sulfoxide comprised of $50 \mathrm{mM}$ cadmium perchlorate, $10 \mathrm{mM}$ lithium perchlorate and 10 $\mathrm{mM}$ sulfur powder. In the case of $\mathrm{ZnSe}$ deposition, cadmium perchlorate is replaced by zinc perchlorate and sulfur powder by selenium powder. Electrodeposition is carried out at $100{ }^{\circ} \mathrm{C}$ with an ac signal of $20 \mathrm{~V}$ at $250 \mathrm{~Hz}$. During the negative half of the ac cycle, the $\mathrm{Cd}^{++}$or $\mathrm{Zn}^{++}$ions in the

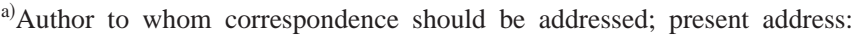
Dept. of Electrical Engineering, Virginia Commonwealth University, Richmond, VA 23284; electronic mail: sbandy@vcu.edu solution are reduced to zero-valent $\mathrm{Cd}$ or $\mathrm{Zn}$ and are deposited selectively in the pores which offer the least impedance path for the electric current to flow. During the positive cycle, the zero-valent metals are not re-oxidized into the ions since alumina is a valve metal oxide. ${ }^{1}$ The high temperature of the solution then allows $\mathrm{Cd}$ or $\mathrm{Zn}$ in the pores to react with $\mathrm{S}$ or $\mathrm{Se}$ in the solution to produce $\mathrm{CdS}$ or $\mathrm{ZnSe}$. The deposition is made to last a few minutes so that the length of the $\mathrm{CdS}$ or $\mathrm{ZnSe}$ nanowires within the pores is a few microns. These nanowires are cylindrical with nominal lengths of a few microns and nominal diameters of either 10 or 50 nm.

The nanowires produced by the above method are not directly suitable for current-voltage measurements because they cannot be contacted easily. Particularly bothersome is the presence of an alumina "barrier layer" in contact with the aluminum substrate (see Fig. 1) which presents a large potential barrier to current flow along the wire axis. We therefore carry out a series of steps to remove the barrier layer and make the wires electrically accessible. These steps are shown in Fig. 2. First, the top surface of the sample is etched for a few minutes in $0.2 \mathrm{M} \mathrm{H}_{2} \mathrm{CrO}_{4} / 0.4 \mathrm{M} \mathrm{H}_{3} \mathrm{PO}_{4}$ solution. This dissolves the alumina and exposes the top of some of the semiconductor wires. Not all wires are exposed since the wires have varying lengths. A thin coating of $\mathrm{Au}$ $(10-20 \mathrm{~nm})$ is then applied on the surface, followed by a thick organic layer which provides mechanical strength to the film during later processing steps. The aluminum substrate is then dissolved in $\mathrm{HgCl}_{2}$ to expose the barrier layer of alumina which is subsequently removed in $5 \% \mathrm{H}_{3} \mathrm{PO}_{4}$ (several minutes of soaking) thereby exposing some of the semiconductor nanowires from the bottom. The sample is flipped over and the bottom layer is coated with $10-20 \mathrm{~nm}$ of $\mathrm{Au}$. The final structures are arrays of parallel nanowires with $\mathrm{Au}$ ohmic contacts at both ends. Gold wires and silver paint are used to connect the Au contacts to the measuring equipment.

The current-voltage characteristic of $10 \mathrm{~nm}$ diam wires (in the presence and absence of IR radiation) is shown in Fig. 3(a). The resistances of all samples increase significantly, by up to a factor of 160, when exposed to IR radiation. This is not a sample heating effect which can only produce a change 


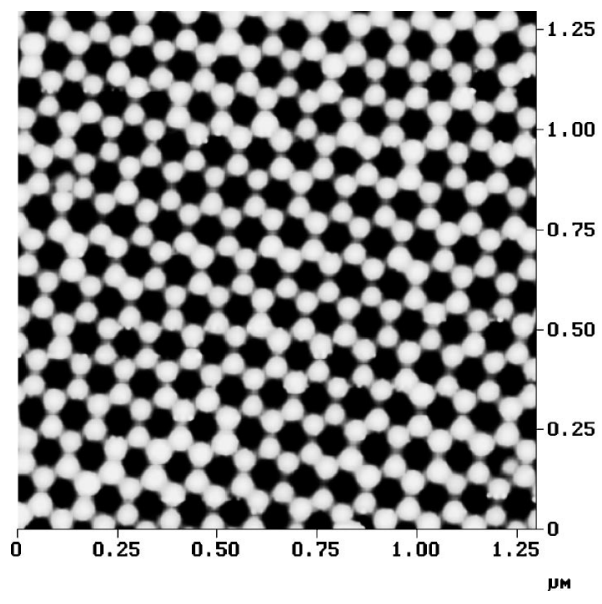

of a few percent in resistance. In any case, the radiation intensity is low enough to avoid measurable sample heating. In Fig. 3(b), we show the characteristics for a "blank" alumina film (with no semiconductor in it) to ascertain that the photoresistive behavior is indeed due to the semiconductor and not due to the alumina. Note that the alumina shows a weak photoconductivity as opposed to photoresistivity, i.e., the behavior is opposite to that of semiconductors; the conductance is slightly larger, rather than smaller, when the IR radiation is on. The ratio of dark to illuminated current $\left(I_{\text {dark }} / I_{\mathrm{IR}}\right)$ for 10 and $50 \mathrm{~nm}$ diam CdS and ZnSe nanowires is shown in Fig. 3(c) as a function of applied voltage.

The photoresistive behavior described here most likely accrues from photoassisted real-space transfer of electrons from the semiconductor nanowires into traps in the surrounding alumina. The majority of carriers in the semiconductor nanowires are electrons as has been verified in the past by capacitance-voltage spectroscopy. ${ }^{5}$ Many of these electrons absorb infrared photons and are excited to trap levels in the

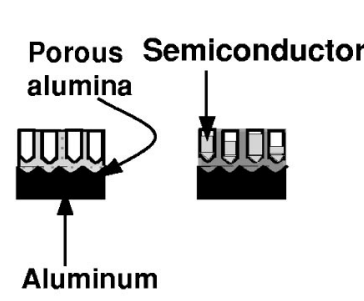

(a)

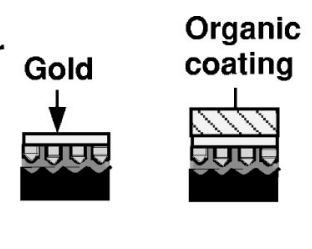

(c)

(d) alumina where they get trapped and can no longer contribute to conduction. As a result, the resistance rises. This process is depicted in Fig. 4(a). It is an indirect process in real space, but the wave functions of electrons in the semiconductors penetrate a short distance into the alumina, thereby making the matrix element of this process significant at the interface between the semiconductor and alumina.

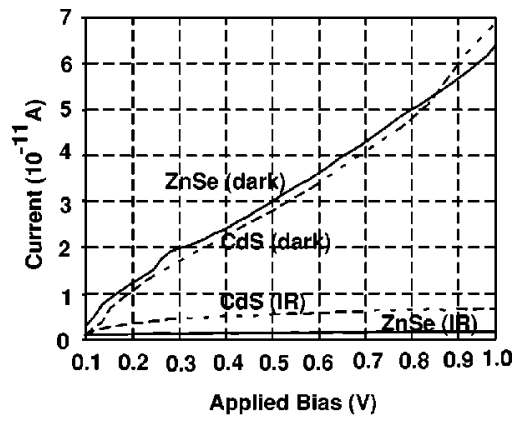

(a)

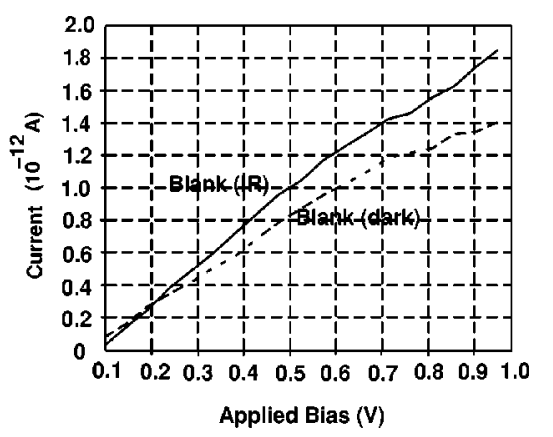

(b)

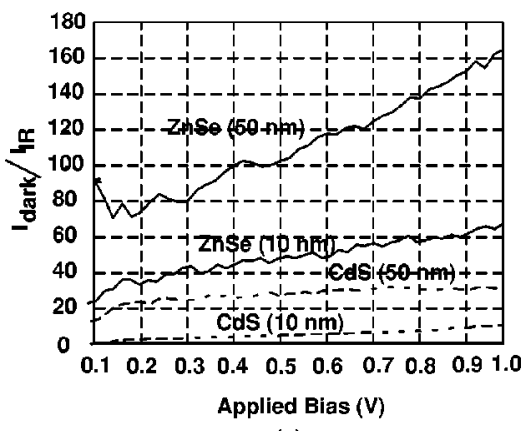

(c)

FIG. 3. (a) Current-voltage characteristics of $10 \mathrm{~nm}$ diam wires, (b) Current-voltage characteristics of blank alumina templates, and (c) the ratio of dark-to-illuminated current as a function of applied bias. 


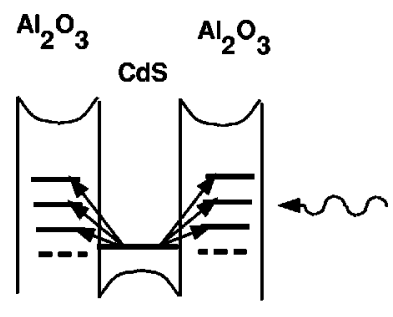

(a)

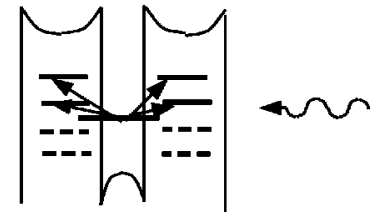

(b)
FIG. 4. (a) Energy band diagram explaining photoabsorption of electrons from the semiconductor conduction band into traps in the band gap of alumina. (b) Fewer traps states are available as final states in narrower wires. Traps which are below the lowest subband level in the semiconductor wire (and therefore not accessible as final states) are shown by broken lines.

An interesting feature is that the larger diameter $(50 \mathrm{~nm})$ wires show a stronger photoresistive effect (larger ratio of dark-to-illuminated conductance) than the smaller diameter $(10 \mathrm{~nm})$ wires. This can be explained within a simple band picture [see Fig. 4(b)]. When the wire is narrower, the subband level in the wire is higher in energy so that fewer trap levels in the insulator are now above the subband level and accessible. Thus, fewer carriers can transfer out of the wire into the traps, and the photoresistive effect is weaker. This picture is substantiated by the IR absorption spectra for 10 and $50 \mathrm{~nm}$ diam wires shown in Figs. 5(a) and 5(b). The integrated absorption is always much larger for the wider

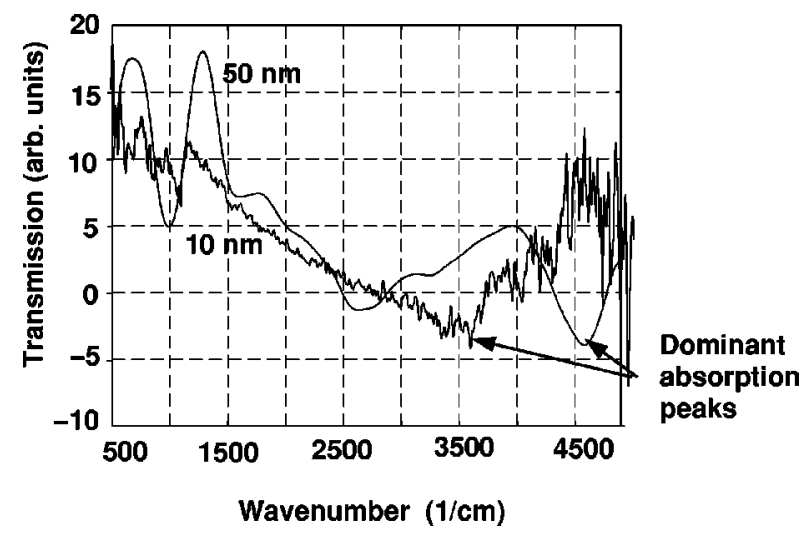

(a)

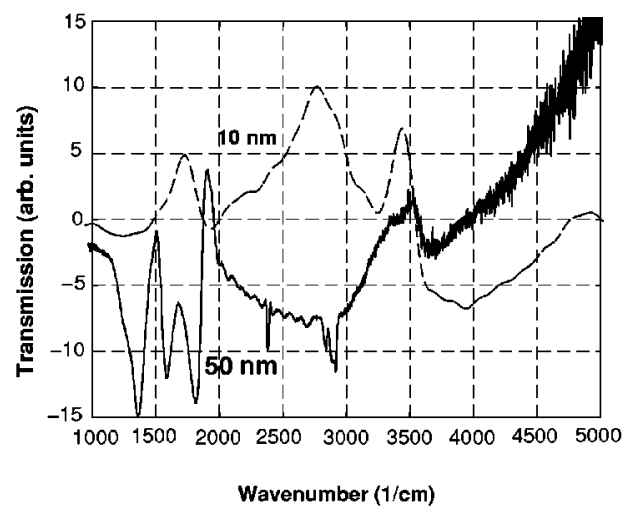

(b)

FIG. 5. Infrared absorption spectra in (a) CdS nanowires and (b) ZnSe nanowires. In some cases, the spectrum was smoothed to eliminate spurious interference effects. diameter wires showing that more trap levels are participating in their case.

Note that if there is a "dominant trap level" causing a dominant absorption peak, then it will be redshifted in the narrower wire since the energy separation between the subband level and the trap states decreases as the wire gets narrower. The redshift is clearly observed in the CdS wires [Fig. 5(a)] where there is a dominant peak. The spectrum for $\mathrm{ZnSe}$, on the other hand, is much more complex (obviously because of a more complex distribution of traps in energy space) and does not show a dominant peak indicating that there is no single dominant trap level at the $\mathrm{ZnSe} / \mathrm{Al}_{2} \mathrm{O}_{3}$ interface. Little, if anything, is known about trap levels at the interface of electrodeposited semiconductors and anodic alumina. They are probably sensitive to electrodeposition and anodization conditions. There are trap states at the $\mathrm{Au}-$ semiconductor interface as well, but this interface is much smaller in area than the interface between the semiconductor and alumina, so these traps are unlikely to have a dominant effect.

In the past, a weak photoresistive effect, for which the conductance dropped by a mere $\sim 10 \%$ (as opposed to the 160 -fold drop reported here), was observed in bulk $\mathrm{CdS}$ and ZnSe samples, ${ }^{6,7}$ but was due to an entirely different mechanism. There, electrons were photoexcited by the IR radiation from the valence band into intentionally created empty traps in the band gap. The resulting holes in the valence band recombined with electrons in the conduction band to drop the conductance by $10 \%$. We do not have any intentionally created traps. Furthermore, capacitance voltage spectroscopy has shown ${ }^{5}$ that the trap concentration is small enough in our samples that the Fermi level is completely unpinned. In any case, all traps in the band gap must be filled because we have significant electron concentration in the conduction band, meaning that the Fermi level must be close to the conduction band edge. Thus, our effect cannot be explained by the same mechanism as that in Refs. 6 and 7. That mechanism is a two-step process: photoexcitation of electrons into traps (or, equivalently, photoemission of holes from traps), followed by recombination of those holes with electrons in the conduction band. Ours is a one-step process that only involves trapping and no recombination.

This work was supported by the Office of Naval Research under Grant No. N00014-01-1-0742.

\footnotetext{
${ }^{1}$ See, for example, D. AlMawlawi, N. Coombs, and M. Moskovitz, J. Appl. Phys. 70, 4421 (1991).

${ }^{2}$ N. Kouklin, S. Bandyopadhyay, S. Tereshin, A. Varfolomeev, and D. Zaretsky, Appl. Phys. Lett. 76, 460 (2000).

${ }^{3}$ A. Balandin, S. Bandyopadhyay, P. G. Snyder, S. Stefanovich, A. Varfolomeev, D. Zaretsky, G. Banerjee, and A. E. Miller, Phys. Low-Dimens. Semicond. Struct. 11/12, 155 (1997).

${ }^{4}$ S. Bandyopadhyay and A. E. Miller, in Handbook of Advanced Electronic and Photonic Materials and Devices, edited by H. S. Nalwa (Academic, San Diego, 2001), Vol. 6, Chap. 1, pp. 1-27; see also numerous references therein.

${ }^{5}$ N. Kouklin and S. Bandyopadhyay, in Proceedings of the 2000 IEEE International Symposium on Compound Semiconductors (IEEE, Piscataway, NJ, 2000), pp. 303-308.

${ }^{6}$ K. H. Schoenbach, V. K. Lakdawala, R. K. F. Germer, and S. T. Ko, J. Appl. Phys. 63, 2460 (1988).

${ }^{7}$ R. K. F. Germer, K. H. Schoenbach, and S. G. E. Pronko, J. Appl. Phys. 64, 913 (1988).
} 